\title{
ACTIVIDAD ANTIFÚNGICA DE COMPUESTOS FENÓLICOS DE TARA (Caesalpinia spinosa) FRENTE A Fusarium graminearum
}

\author{
ANTIFUNGAL ACTIVITY OF TARA (Caesalpinia spinosa) \\ PHENOLIC COMPOUNDS AGAINST Fusarium graminearum
}

\author{
1 Mateo David León Durán, 2 Myriam Ximena Mancheno Cárdenas \\ ${ }^{1}$ Magister en Ciencias - Biotecnología, Universidad Nacional, Medellín, Colombia. \\ ${ }^{2}$ Magister en Sistemas Integrados en Gestión de la Calidad, Ambiente y Seguridad, \\ Universidad Politécnica Salesiana, Cuenca, Ecuador. \\ ${ }^{1}$ matleon@unal.edu.co, ${ }^{2}$ mmancheno@ups.edu.ec
}

\section{RESUMEN}

Contextualización: Fusarium graminearum es un microorganismo de campo que afecta a gramíneas y causa grandes pérdidas, particularmente a cultivos de arroz. Para contrarrestar estos problemas fitosanitarios se aplican cantidades excesivas de plaguicidas, lo que causa daños a la salud y el ambiente. Una alternativa son los extractos vegetales con alto contenido de compuestos bioactivos.

Vacío de conocimiento: los taninos tipo pirogalol contenidos en las vainas de Caesalpinia spinosa poseen propiedades biológicas, la inhibición del crecimiento micelial de Fusarium graminearum es efectiva en concentraciones bajas de UFC/ml.

Propósito del estudio: el objetivo de esta investigación fue determinar in vitro la actividad antifúngica de los compuestos fenólicos de la tara (Caesalpinia spinosa) frente a Fusarium graminearum.
Metodología: en primer lugar, se extrajeron los compuestos fenólicos por maceración y calentamiento $\left(60^{\circ} \mathrm{C}\right)$ mediante agua y una mezcla agua-etanol. Se determinó el contenido de compuestos fenólicos en los extractos mediante el método de Folin-Ciocalteu. En segundo lugar, se aisló una cepa de Fusarium obtenida de un cultivo de arroz y se identificó por claves taxonómicas; después, se realizaron suspensiones celulares con concentraciones $10^{7}$ y $10^{6} \mathrm{UFC} / \mathrm{ml}$. Para la evaluación in vitro, un disco con inóculo de cada suspensión se colocó en medio cultivo agar papa dextrosa que contenía extracto de Caesalpinia spinosa.

Resultados y conclusiones: el extracto acuoso por calentamiento con un contenido de 5,88 $\mathrm{g}$ ácido gálico/100 g muestra seca inhibió 30 y $70 \%$ de crecimiento micelial de Fusarium graminearum a una concentración de $10^{7}$ y $10^{6} \mathrm{UFC} / \mathrm{ml}$ respectivamente. Compuestos 
fenólicos de Caesalpinia spinosa presentaron propiedades de interés para el control de Fusarium graminearum y pueden ser ensayados in vivo e invernadero.

Palabras clave: compuestos fenólicos; fitopatógeno; Fusarium graminearum; inhibición

\section{ABSTRACT}

Contextualization: Fusarium graminearum is a field microorganism that affects grasses and causes great losses, particularly to rice crops. To counter these phytosanitary problems, excessive amounts of pesticides are applied, causing damage to health and the environment. An alternative is to plant extracts with a high content of bioactive compounds.

Knowledge gap: The pyrogallol tannins contained in Caesalpinia spinosa pods have biological properties, Fusarium graminearum's micellial growth inhibition is effective at low concentrations of UFC/ml.

Purpose: Therefore, the objective in this research was to determinate in vitro the antifungal activity of tare phenolic compounds (Caesalpinia spinosa) against Fusarium graminearum.
Methodology: Firstly, the phenolic compounds extracted by maceration and heating $\left(60^{\circ} \mathrm{C}\right)$ through water and ethanol-water mix, the phenolic compounds content in the extracts determined by Folin-Ciocalteu method. Secondly, a Fusarium strain obtained from a rice culture isolated and identified by taxonomic keys, after cell suspensions made with concentrations $10^{7}$ and $10^{6} \mathrm{UFC} / \mathrm{ml}$. For in vitro evaluation, a disc with an inoculum of each suspension placed in a culture medium containing $C$. spinosa extract.

Results and conclusions: Consequently, the aqueous extract by heating with a content of $5.88 \mathrm{~g}$ gallic acid/100 g dry sample inhibited 30 and $70 \%$ of mycelial growth of Fusarium graminearum with a concentration of $10^{7}$ and $10^{6}$ UFC $/ \mathrm{ml}$. Phenolic compounds of Caesalpinia spinosa have properties of interest for the control of Fusarium graminearum and can be tested in vivo, in the greenhouse.

Keywords: Fusarium graminearum; inhibition; phenolic compounds; phytopathogen

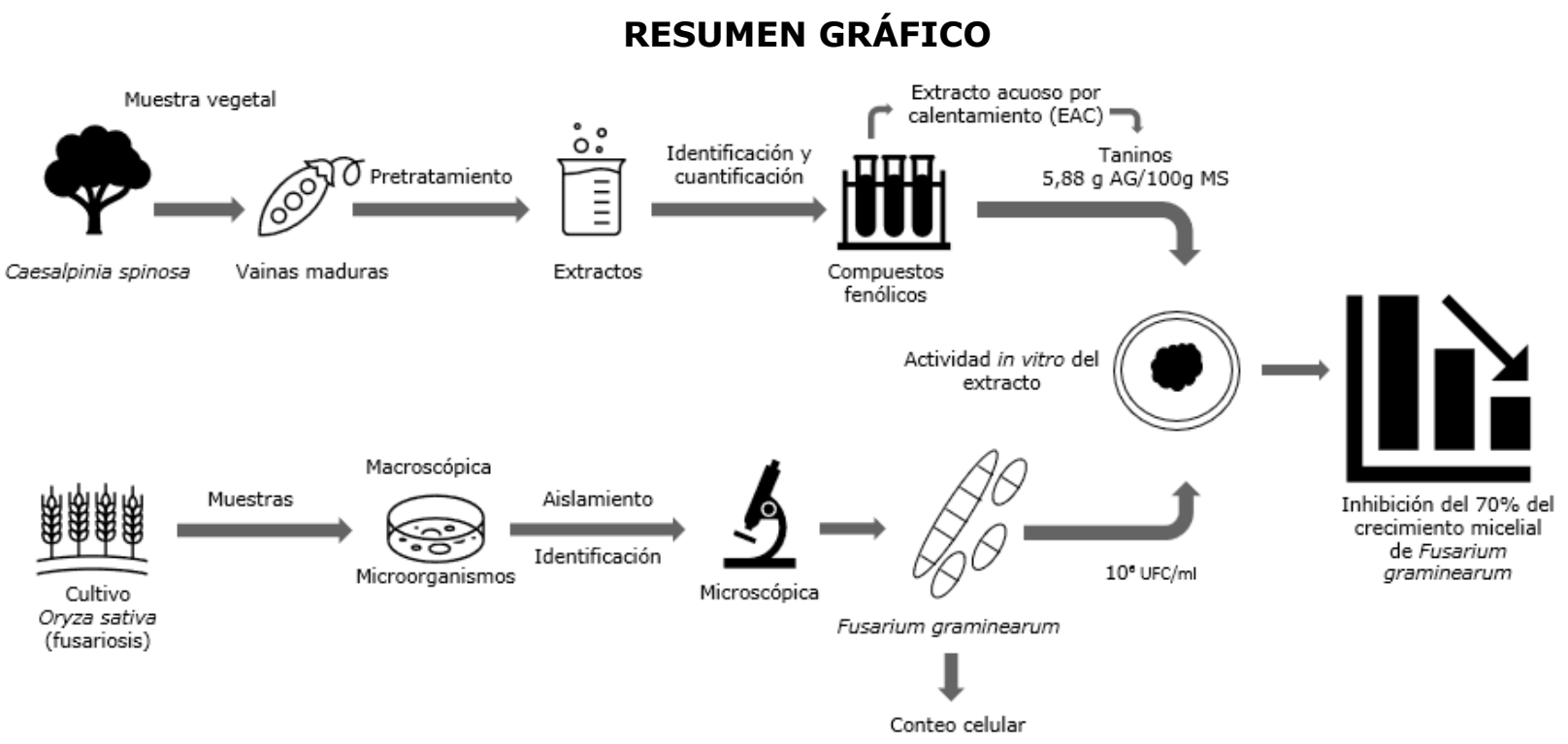

Fuente: Autores. 


\section{INTRODUCCIÓN}

Un cultivo transitorio que se ve afectado por el ataque de microorganismos en el campo es el arroz, un cereal de importancia mundial que es un alimento básico para aproximadamente 3,500 millones de personas (Muthayya et al., 2014). En el 2017 se produjeron aproximadamente 503 millones de toneladas métricas ( $\mathrm{t}$ ) en todo el mundo (FAO, 2018). Entre 2016 y 2017 (de abril a mayo) en Ecuador, la producción de arroz fue de 660 mil t; 90 mil t menos que durante el periodo 2015 - 2016. Esta diferencia ocurrió a causa del fenómeno del Niño y el ataque de plagas y enfermedades (Beillard \& Vega, 2016). Se ha demostrado la presencia de Bipolaris oryzae, Fusarium sp., Phoma sp., Phyllosticta sp., agentes causales de enfermedades en el grano que disminuyen la producción de arroz (Solis, 2016).

Por su parte, especies del género Fusarium se consideran principalmente como hongos de campo (Villa et al., 2014); son de particular estudio porque pueden causar hasta el $90 \%$ de pérdidas en la cosecha (Briones, 2014) en monocultivos, como es el caso del arroz, y afectan la envoltura ocasionando la pudrición de la misma (Villanueva et al., 2013; Bigirimana et al., 2015). Los síntomas de Fusarium graminearum en etapa de floración del arroz son manchas de color café claro en las glumas; posteriormente, evolucionan a lesiones marrones de tamaño y formas irregulares; en la etapa de llenado, las glumas son de color purpura; y para la cosecha, los granos maduros tienen color marrón oscuro (Tabarelli et al., 2019). Actualmente, el control de microorganismos fitopatógenos se realiza mediante técnicas de agricultura convencional (De León et al., 2013), con efectos negativos para la salud humana y daños al medio ambiente. Nuevas investigaciones plantean el uso de plaguicidas botánicos que reemplacen gradualmente a determinados plaguicidas químicos (Nava et al., 2012).
Por consiguiente, los plaguicidas botánicos no generan resistencia y no se bioacumulan en el medio ambiente; son metabolitos secundarios (fitoquímicos) extraídos de diferentes fuentes vegetales (Laxmishree \& Nandita, 2017). Los compuestos bioactivos se componen de alcaloides, taninos, fenoles, flavonoides, terpenos, entre otros (De León et al., 2013). Los compuestos fenólicos tienen varios propósitos en las plantas pero destacan la pigmentación y resistencia a patógenos (Schöneberg et al., 2018).

Por lo tanto, extractos como etanólicos de Glycyrrhiza glabra y Myroxylon balsamum exhibieron actividad antifúngica frente a Fusarium guttiforme (Cerqueira et al., 2015). Extractos de acetato de etilo y metanólicos de Adenophyllum aurantium y Alloispermum integrifolium reducen el crecimiento micelial y esporulación de Fusarium solani y Alternaria alternata (De León et al., 2014). Extractos etanólicos de Phlomis fruticosa poseen actividad inhibitoria contra Aspergillus niger, Fusarium tricintum, Trichoderma viride (Soković et al., 2013).

En particular, la tara (Caesalpinia spinosa), un arbusto de tipo leguminosa originario del Perú que predomina en zonas secas y valles interandinos de Suramérica (He et al., 2016), se aprovecha en la industria química (taninos), alimenticia (aditivo hidrocoloide) y farmacéutica (ácido gálico, antioxidante) (Melo et al., 2013). Los taninos de C. spinosa son usados en medicina tradicional por sus propiedades antiinflamatorios, antimicóticos, antibacterianos, antisépticos, antitumorales y antioxidantes (Murga et al., 2016); su contenido de taninos está en un rango de 0,2 a $25 \%$ del total de masa seca, dependiendo de la especie vegetal, tiempo de cosecha, hábitat y método de extracción (Cuong et al., 2020). 
El objetivo de este estudio fue determinar in vitro la actividad antifúngica de los compuestos fenólicos de tara (Caesalpinia spinosa) frente a Fusarium graminearum.

\section{MATERIALES Y MÉTODOS}

\subsection{Muestra vegetal y extractos crudos}

Se recolectaron vainas completamente maduras de Caesalpinia spinosa mediante el método convencional en el municipio de Guachapala, perteneciente a la provincia del Azuay, durante el mes de abril del 2017; se seleccionaron cinco árboles al azar y, en total, se colectaron $5 \mathrm{~kg}$ de muestra.

El material vegetal fue secado a temperatura ambiente durante cinco días; posteriormente, se separaron las semillas de la vaina. En este caso, las semillas no se tuvieron en cuenta. Para la obtención de la harina de $C$. spinosa se realizó una molienda fina de las vainas en una licuadora industrial Blender C86, luego se tamizó en un tamiz Advantech Nro. 18 para una granulometría de $1 \mathrm{~mm}$ (Aguilar et al., 2012).

- Extracto acuoso por maceración (EAM) En un frasco de vidrio se colocaron 0,4 $\mathrm{g}$ de harina de $C$. spinosa con $70 \mathrm{ml}$ de agua destilada; después, se dejó en reposo y oscuridad durante $72 \mathrm{~h}$ a temperatura ambiente; posteriormente, se filtró y se llevó el extracto a un balón de aforo de $100 \mathrm{ml}$ (Rodríguez et al., 2012).

- Extracto acuoso por calentamiento (EAC) En un vaso de precipitación se colocaron $0,4 \mathrm{~g}$ de harina de $C$. spinosa con $70 \mathrm{ml}$ de agua destilada, la mezcla se calentó a $60{ }^{\circ} \mathrm{C}$ por $10 \mathrm{~min}$, luego se filtró y el extracto se llevó a un balón de aforo de $100 \mathrm{ml}$ (Játiva, 2011).

- Extracto hidroalcohólico 30\% por maceración (EHM) En un frasco de vidrio se colocaron $0,4 \mathrm{~g}$ de harina de $C$. spinosa con $70 \mathrm{ml}$ de una solución etanólica
30\%; luego, se dejó en reposo por 72 h a temperatura ambiente; posteriormente se filtró y el extracto se llevó a un balón de aforo de $100 \mathrm{ml}$ (Rodríguez et al., 2012).

\subsection{Identificación y cuantificación de compuestos fenólicos (CF)}

En un tubo de ensayo se colocó $1 \mathrm{ml}$ de cada extracto; particularmente, para el extracto acuoso se adicionó una pequeña cantidad de acetato de sodio. Después, se dosificaron a cada muestra 3 gotas de cloruro férrico $5 \%$, la prueba es positiva cuando desarrollan una coloración azul oscura (Delporte, 2010).

Previamente, se disolvió el extracto en una proporción 1:10; en un frasco ámbar, se colocaron $50 \mu \mathrm{l}$ de muestra, $3950 \mu \mathrm{l}$ de agua destilada, $250 \mu \mathrm{l}$ de reactivo de Folin - Ciocalteu; luego de 2 min, se adicionaron $750 \mu l$ de carbonato de sodio $20 \%(\mathrm{v} / \mathrm{v})$; posteriormente se dejaron reposar por $1 \mathrm{~h}$ y se midieron a 750 nm la absorbancia.

La curva de calibración se realizó empleando ácido gálico, como estándar, a concentraciones de 200, 150, 100 y 50 ppm. La ecuación de la curva de calibración corresponde a $\mathrm{Y}=0,007077$ $* X+0,003519, \mathrm{R}^{2}=0,9998$. Las muestras se analizaron usando el espectrofotómetro UV - vis Jasco V - 630, los resultados se expresaron en gramos de ácido gálico/100 g muestra seca ( $\mathrm{g}$ AG/100 g MS) (Flor \& Parra, 2017).

\subsection{Aislamiento, identificación y conteo celular}

Fusarium se aisló de un cultivo de arroz del municipio Arenillas de la provincia el Oro en Ecuador, para la recolección del material biológico se consideraron plantas con fusariosis en la espiga, el diseño de muestreo fue en forma de $\mathrm{X}$ que consiste en tomar muestras de cada esquina y del centro de la parcela, por cada 
punto se seleccionaron al azar 20 plantas, en total se tomó $1 \mathrm{~kg}$ de muestra; granos infectados se sumergieron en etanol $70 \%$ e hipoclorito de sodio $1 \%$ cada uno por 2 min; posteriormente se colocaron en medio de cultivo agar papa dextrosa (PDA) con 50 ppm de gentamicina, en total 10 cajas Petri se incubaron a 26,5 ${ }^{\circ} \mathrm{C}$ por $7 \mathrm{~d}$ (Arbito, 2017).

La identificación del hongo se realizó mediante claves taxonómicas establecidas por (Leslie \& Summerell, 2006) se analizaron características macroscópicas del micelio: color, aspecto y pigmentación del agar, y características microscópicas como: macroconidias, microconidias y clamidiosporas.

Después del lavado de esporas se preparó una suspensión celular de Fusarium graminearum en agua destilada (el cultivo debía estar en el día 7), y luego se realizó una dilución 1:10 y se colocó una muestra en la cámara de Neubauer. Con la ayuda del microscopio de pantalla Micros Austria se realizó por triplicado el conteo de conidios (Lage et al., 2013).

\subsection{Evaluación in vitro}

En medios de cultivo PDA previo a su gelificación se adicionó $5 \mathrm{ml}$ de EAC, luego se implantó un disco con la concentración total de células y/o la dilución 1:10. El control fue inóculo de Fusarium graminearum en un medio PDA sin extracto. Las cajas se mantuvieron a $26,5^{\circ} \mathrm{C}$ por $7 \mathrm{~d}$ en una estufa Mermmet, cada ensayo se realizó por triplicado.

La capacidad inhibitoria se determinó por la superficie de crecimiento del micelio en $\mathrm{cm}^{2}$ : ((Área control - Área tratamiento)/(Área control)). Para obtener los valores correspondientes se consideró el diámetro promedio debido a que el crecimiento de los hongos es radial pero no uniforme (Schöneberg et al., 2018).

\subsection{Análisis estadístico}

Todos los datos obtenidos se analizaron con el software estadístico libre $R$ versión 3.5.2. Los resultados del contenido de compuestos fenólicos en los extractos y la influencia sobre el crecimiento micelial radial se presentaron como medias \pm desviación estándar. Diferencias entre tratamientos tanto para los extractos como para la inhibición in vitro se evaluaron con el modelo ANOVA de una vía (aov\{stats\}), con un nivel de significancia de 0,05 . Los supuestos de normalidad y homogeneidad de varianzas se evaluaron con la prueba de Shapiro-Wilk (shapiro.test\{stats\}) y prueba de Levene (leveneTest\{car\}), respectivamente. Se realizaron comparaciones múltiples por parejas por la prueba de diferencia significativa honesta de Tukey (HSD.test\{agricolae\}) y los resultados se expresaron como intervalos de confianza al $95 \%$.

\section{RESULTADOS Y DISCUSIÓN}

\subsection{Compuestos fenólicos en extractos}

Los extractos acuosos e hidroalcohólico presentaron diferentes coloraciones de amarillo leve a amarillo - café, esto se da por la presencia de compuestos tánicos; además se observaron flóculos de color blanco que se atribuyeron a gomas y resinas que posee $C$. spinosa; De la Cruz (2004) definió a estas gomas o hidrocoloides como biopolímeros que poseen efectos gelificantes.

Los extractos acuosos e hidroalcohólico mostraron una coloración azul oscura, igual característica obtuvieron en Caesalpinia spinosa (Cortez, 2012) y en Raputia heptaphylla (Coy et al., 2014), esta coloración indica que, en las muestras existen taninos del tipo pirogalol. Los taninos son compuestos fenólicos solubles en agua que se dividen en hidrolizables (galotaninos y elágitaninos) presentes en Caesalpinia sp y condensados (proantocianidinas) presentes en Acacia sp (Anttila et al., 2013; Fraga 
et al., 2020). De acuerdo a Skowyra (2014) el principal componente de los taninos de $C$. spinosa son basados en el ácido galoilquinico, del cual derivan el ácido gálico, ácido quinico y grupos galoil.

Mediante el método de Folin - Ciocalteu el contenido de CF en EAM, EAC y EHM fueron 4,77 - 5,88 - 4,76 g AG/100 g MS respectivamente (Figura 1). Diferencias entre tratamientos $\mathrm{p}=$ 0,0306 . Según la prueba Tukey con el tratamiento EAC, se obtuvo un mayor contenido de CF. Según Markom et al., (2007) los taninos hidrolizables se extraen preferentemente con agua o mezclas agua - etanol, razón por la cual EAM y EHM presentaron contenido similar de compuestos bioactivos. Por otro lado, EAC fue superior debido a que al adicionar energía (60 $\left.{ }^{\circ} \mathrm{C}\right)$ a la extracción se reducen la viscosidad y tensión superficial (Markom et al., 2010) permitiendo que los taninos se liberen de la matriz vegetal debido a la inestabilidad existente (Wang et al., 2019; Cuong et al., 2020). Otra propiedad de los solventes es la constante dieléctrica, agua destilada 78,5 $\mathrm{Fm}^{-1}$ y etanol es $24,5 \mathrm{Fm}^{-}{ }^{1}$; según (Cortez, 2012) un solvente con mayor constante dieléctrica extrae mayor contenido de metabolitos secundarios.

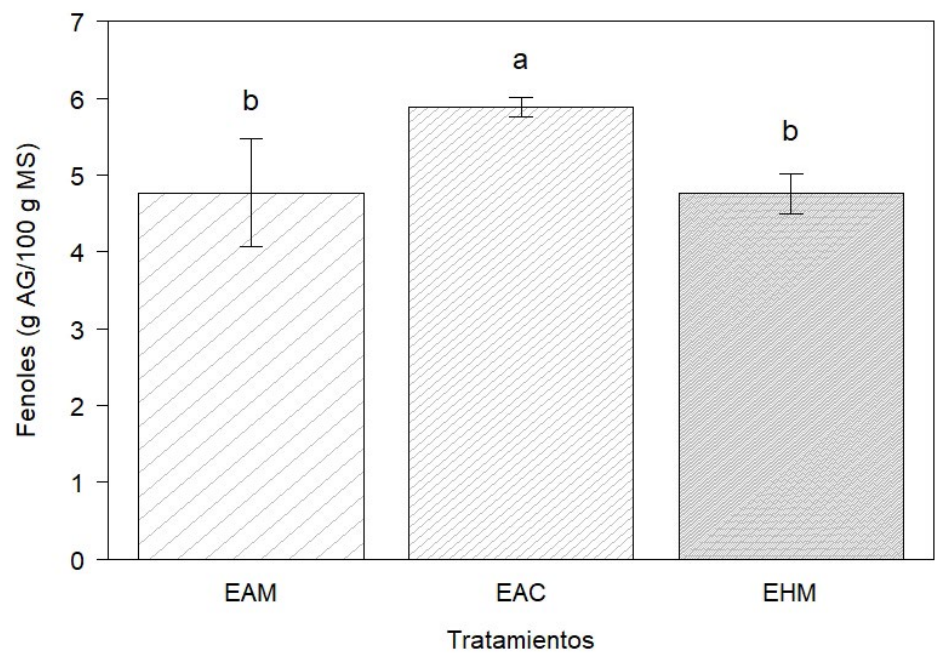

Figura 1. Los resultados del contenido de compuestos fenólicos (CF) en C. spinosa se expresan como el promedio de g AG/100 g MS \pm DS. Comparación de CF se realizó entre los diferentes tratamientos: extracto acuoso por maceración (EAM), extracto acuoso por calentamiento $60{ }^{\circ} \mathrm{C}$ (EAC) y extracto hidroalcohólico por maceración 30\% (EHM). Tratamientos con una letra común no difieren en un nivel del 5\%, según la prueba DSH de Tukey.

Fuente: Autores.

En C. spinosa Kardel et al., (2013) de determinaron por colorimetría taninos condensados $4,6 \mathrm{mg} / \mathrm{g}$ en extractos butanol-ácido clorhídrico; sin embargo, en extractos por agua caliente analizados en HPLC-MS la concentración de taninos hidrolizables fue $647 \mathrm{mg} / \mathrm{g}$ de equivalentes de epigalocatequina galato; Játiva (2011) y Cortez (2012) con extractos acuosos obtuvieron 42 y 23 g AG/100 g MS respectivamente. Cabe mencionar que las muestras fueron tomadas de árboles que se encontraban en Ecuador. Por otro lado, Avilés et al., (2010) obtuvieron en extractos acuosos e hidroalcohólicos 11 y $15 \mathrm{~g} \mathrm{AG/100} \mathrm{g} \mathrm{MS} \mathrm{respectivamen-}$ te, las muestras fueron extraídas de árboles que se encontraban en Perú. Los resultados 
del contenido de CF difieren a lo reportado en la literatura, por factores externos los cuales condicionan a la especie vegetal; según Nuñez et al., (2017) las características del suelo y las condiciones climáticas influyen en la acumulación de compuestos fenólicos; de acuerdo a Nieto \& Barahona (2006) los requerimientos para C. spinosa son: suelos franco arenosos, temperatura 13 a $22{ }^{\circ} \mathrm{C}$, humedad relativa < $80 \%$ y precipitaciones < $750 \mathrm{~mm}$. Una posible causa para el bajo contenido de CF son las condiciones del suelo, debido a que los árboles seleccionados en el muestreo se encontraban en una zona con abundante materia orgánica.

\subsection{Identificación y conteo celular de Fusarium}

Las claves taxonómicas determinaron que el hongo aislado fue Fusarium graminearum, y sus características macroscópicas fueron: micelio bien desarrollado de aspecto lanudo algodonoso y de crecimiento rápido; las coIonias inicialmente fueron de color blanco, transcurridos los días se tornaron de color crema; en el reverso de la caja Petri el color fue pardo; además, ciertos cultivos presentaron pigmentos rojos en el agar. Por otro lado, las características microscópicas fueron: macroconidia delgada, paredes gruesas, ligeramente curvada, septos entre 4 y 6 , célula basal en forma de pie y célula apical cónica, en esta especie hay ausencia de microconidias y clamidiosporas (Figura 2) (Melgarejo et al., 2010; Refai et al., 2015). Pacin et al., (2002) determinaron la presencia de $F$. graminearum en cultivos de arroz en la región costera de Ecuador.

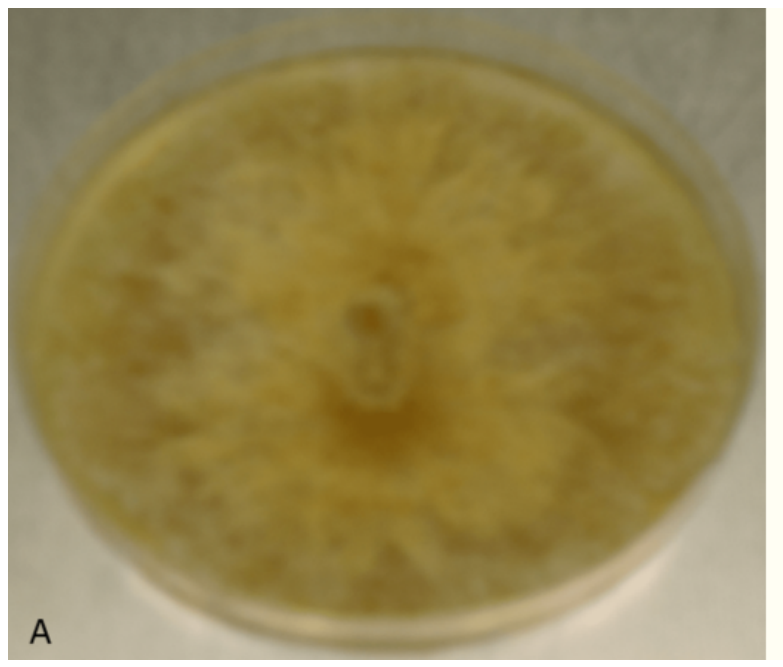

B

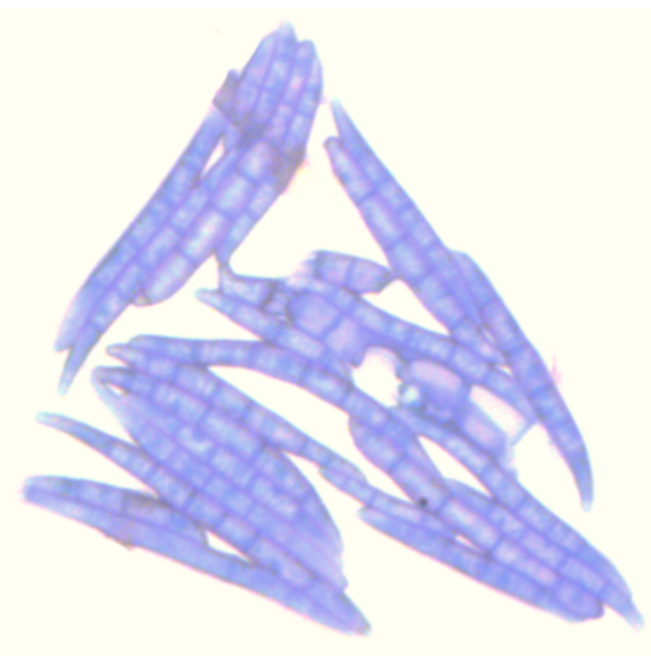

Figura 2. A: Fusarium graminearum con micelio lanudo algodonoso, colonia de color crema; B: Macroconidia: curva típica septada, célula basal en forma de pie y célula apical cónica. Lente de inmersión 100x.

Fuente: Autores.

A través del conteo de células por cámara de Neubauer se obtuvo una concentración aproximada a $10^{7} \mathrm{UFC} / \mathrm{ml}$; por ende, la dilución $1: 10$ tiene una concentración cercana a $10^{6}$ UFC/ml. Con cultivos de $F$. oxysporum y $F$. solani el día nueve (Lage et al., 2013) obtuvieron concentraciones 1,8 y 2,8 $10^{6} \mathrm{UFC} / \mathrm{ml}$, esto demostró la alta capacidad de esporulación de $F$. graminearum.

\subsection{Actividad in vitro del extracto}

La actividad inhibitoria del EAC frente a Fusarium graminearum en concentración total - $10^{7}$ UFC/ $\mathrm{ml}$ (CT) y concentración diluida - $10^{6} \mathrm{UFC} / \mathrm{ml}$ (CD) 
se expresaron como la superficie de crecimiento del micelio ( $\left.\mathrm{cm}^{2}\right)$, control 26,44; (CT+EAC) 18,38 y (CD+EAC) 7,89 (Figura 3). Para una mejor comprensión los valores, se convirtieron en porcentaje de inhibición, control no presentó; (CT+EAC)
$30,6 \%$ y (CD+EAC) 70,3\%. Diferencias entre tratamientos $\mathrm{p}=6,18 \mathrm{e}^{-5}$ ). De acuerdo con la prueba Tukey con el tratamiento (CD+EAC) se obtuvieron mayores porcentajes de inhibición frente al fitopatógeno (Figura 4).
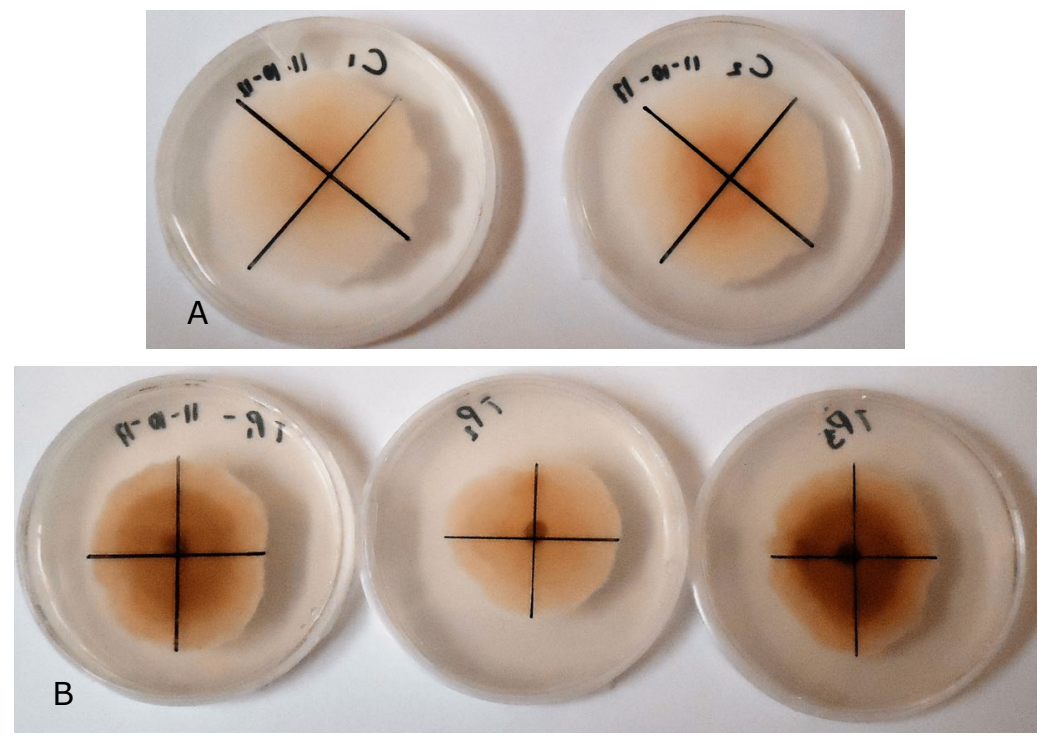

Figura 3. Crecimiento micelial de Fusarium graminearum. A: Control, B: $10^{7} \mathrm{UFC} / \mathrm{ml}$ con extracto acuoso por calentamiento (EAC) luego de $7 \mathrm{~d}$ a $26,5^{\circ} \mathrm{C}$.

Fuente: Autores.

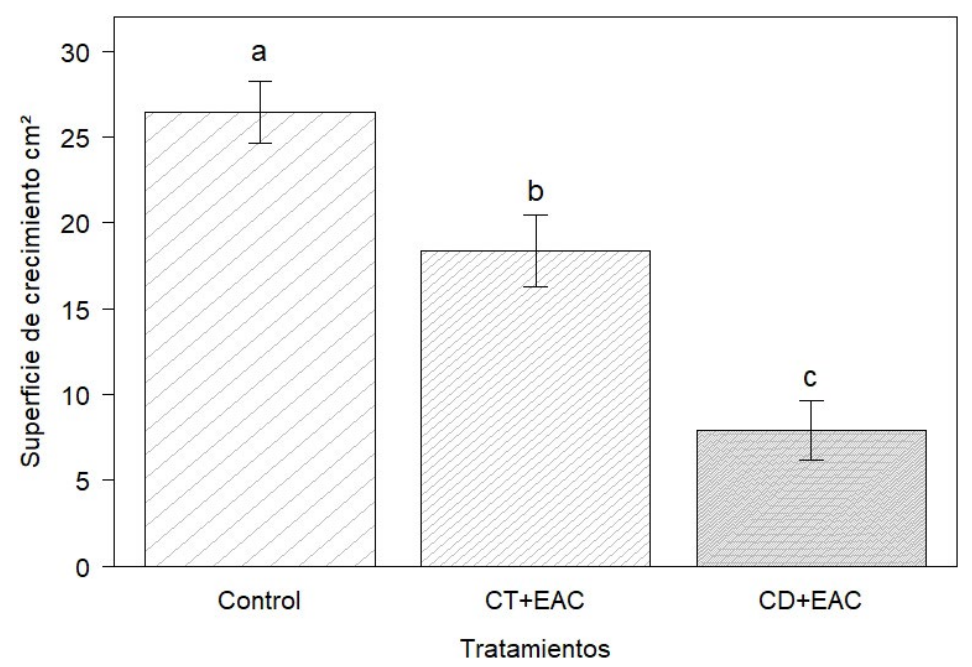

Figura 4. Los resultados se expresan como el promedio de la superficie de crecimiento micelial en $\mathrm{cm}^{2} \mathrm{de}$ Fusarium graminearum $\pm \mathrm{DS}$. Control, $10^{7} \mathrm{UFC} / \mathrm{ml}$ células más extracto acuoso por calentamiento $60{ }^{\circ} \mathrm{C}$ (CT+EAC), $10^{6} \mathrm{UFC} / \mathrm{ml}$ más extracto acuoso por calentamiento $60^{\circ} \mathrm{C}(\mathrm{CD}+\mathrm{EAC})$, luego de $7 \mathrm{~d}$ a $26,5^{\circ} \mathrm{C}$. Tratamientos con una letra común no difieren en un nivel del 5\%, según la prueba DSH de Tukey.

Fuente: Autores. 
En Fusarium sp Veloz et al., (2012) con extractos tánicos de Caesalpinia cacalaco al $1 \%$, se obtuvo una inhibición del $68 \%$; en Penicillium sp Játiva (2011) con extractos tánicos de C. spinosa a 2500 y 5000 ppm consiguieron 53 y $87 \%$ de inhibición respectivamente, las mismas concentraciones fueron aplicadas a Aspergillus niger y no existió inhibición. Extractos polifenólicos de Acacia farnesiana obtuvieron $98 \%$ de inhibición micelial en Fusarium oxysporum Rodríguez et al., (2012).

En esta investigación se determinó que EAC de C. spinosa frente a $10^{6} \mathrm{UFC} / \mathrm{ml}$ de Fusarium graminearum inhibió $70 \%$ de su desarrollo micelial, esto fue posible debido a que el extracto contenía taninos hidrolizables. Al comparar este resultado con otros autores, se puede asumir que extractos de especies pertenecientes a la familia Fabaceae tienen alta capacidad reducir el crecimiento in vitro de hongos filamentosos.

Extractos crudos de Khaya ivorensis y Tetracera potatoria Adekunle et al., (2003); Asphodelus tenuifolius y Euphorbia guyoniana Salhi et al., (2017); Rhus muelleri Jasso de Rodríguez et al., (2015); Parthenium hysterophorus, Acacia farnesiana y Pluchea carlinensis Rodríguez et al., (2000); Diospyros cuneata Ruiz et al., (2016), contienen compuestos fenólicos, terpénicos y alcaloides con actividad inhibitoria de 60 a $87 \%$ o capacidad fungicida frente a hongos filamentos como F. graminearum, F. oxysporum, F. sporotrichioides, A. niger, T. viride. En las investigaciones citadas la presencia de compuestos fenólicos junto a otros metabolitos secundarios alcanzaron altos porcentajes de capacidad inhibitoria, lo que demuestra gran potencial para controlar determinados fitopatógenos.

\section{CONCLUSIONES}

Los compuestos fenólicos obtenidos del extracto crudo de vainas de $C$. spinosa demostraron tener actividad inhibitoria ante el crecimiento micelial de $F$. graminearum a nivel in vitro. EAC tuvo un contenido de $5,88 \mathrm{~g}$ de AG/100 g MS y la presencia de taninos tipo pirogalotánicos; mediante revisión de literatura se establecieron que las muestras son ricas en taninos hidrolizables. Respecto a la actividad antifúngica, se obtuvieron 30 y $70 \%$ de inhibición frente a concentraciones de inóculo $10^{7} \mathrm{UFC} / \mathrm{ml}$ y $10^{6} \mathrm{UFC} / \mathrm{ml}$ respectivamente. Los resultados dan viabilidad a la realización de estudios in vivo en invernaderos, controlando ciertas variables y evaluando el uso de este extracto en un sistema de manejo integrado de plagas.

\section{AGRADECIMIENTOS}

Esta investigación fue desarrollada en los Laboratorios Ciencias de la Vida de la Universidad Politécnica Salesiana sede Cuenca, se agradece a los docentes del Grupo de Investigación y Valoración de la Biodiversidad (GIVABI).

\section{CONTRIBUCIÓN DE LA AUTORÍA}

Primer autor: metodología, investigación, análisis de datos, conceptualización, escritura - borrador original. Segundo autor: logística, supervisión y revisión.

\section{LITERATURA CITADA}

Adekunle, A., Duru, C., y Odufuwa, O. (2003). Antifungal activity and phytochemical screening of the crude extracts of Khaya ivorensis Juss ( Meliaceae ) and Tetracera potatoria L . ( DiIleniaceae ). South African Journal of Botany, 69(4), 568-571. https://doi.org/10.1016/S02546299(15)30296-9

Aguilar, J., Jaén, J., Vargas, A., Jiménez, P., Vega, I., Herrera, J., ... Soto, R. (2012). Extracción y evaluación de taninos condensados a partir de la corteza de once especies maderables de Costa Rica. Tecnología En Marcha, 25(4), 15-22. 
Anttila, A., Pirtila, A., Haggman, H., Harju, A., y Venalainen, M. (2013). Condensed conifer tannins as antifungal agents in liquid culture. $\mathrm{Hol}-$ zforschung, 67(7), 1-8. https://doi.org/10.1515/ hf-2012-0154

Arbito, M. (2017). Evaluación in vitro de la capacidad antagónica de Trichoderma spp. frente a Fusarium spp (tesis de pregrado). Universidad Politécnica Salesiana, Cuenca, Ecuador.

Avilés, R., Carrión, J., Huamán, J., Bravo, M., Rivera, D., Rojas, N., y Santiago, J. (2010). Actividad antioxidante, polifenoles totales y contenido de taninos de extractos de tara, Caesalpinia spinosa. Revista Peruana de Química e Ingeniería Química, 13(2), 5-11.

Beillard, M., y Vega, H. (2016). Ecuador wheat imports, corn and rice production expected to decrease in 2016. Global Agricultural Information Network, 1-12.

Bigirimana, V., Hua, G., Nyamangyoku, O., y Hòfte, M. (2015). Rice sheath rot: an emerging ubiquitous destructive disease complex. Frontiers in Plant Science, 6(1066), 1-16. https://doi. org/10.3389/fpls.2015.01066

Briones, G. (2014). Calidad de semilla de arroz en función de la incidencia y severidad de enfermedades en la zona de Daule (tesis de pregrado). Universidad de Guayaquil, Guayaquil, Ecuador.

Cerqueira, M., Barcellos, H., Machado, P., y Aires, J. (2015). Antifungal activity of plant extracts with potential to control plant pathogens in pineapple. Asian Pacific Journal of Tropical Biomedicine. https://doi.org/10.1016/j.apjtb.2015.09.026

Cortez, D. (2012). Obtención de extracto tánico y extracto gálico a partir de la harina de vaina de guarango (Caesalpinia spinosa) a escala laboratorio (tesis de pregrado). Escuela Superior Politécnica de Chimborazo, Riobamba, Ecuador.

Coy, C., Parra, J., y Cuca, L. (2014). Caracterización química del aceite esencial e identificación preliminar de metabolitos secundarios en hojas de la especie Raputia heptaphylla (rutaceae). Elementos, 4, 31-39. https://doi.org/10.15765/e. v4i4.513

Cuong, D., Hoan, N., Dong, D., Minh, L., Thanh, N., y Ha, H., (2020). Tannins: extraction from plants. In A. Aires. (Ed.), In tannins - structural properties, biological properties and current Knowledge (pp. 1-20). Vila Real, Portugal. https://doi.

\section{org/10.5772/intechopen.86040}

De la Cruz, P. (2004). Aprovechamiento integral y racional de la tara Caesalpinia spinosa - Caesalpinia tinctoria. Revista Del Instituto de Investigación de La Facultad de Ingeniería Geológica, Minera, Metalurgica y Geográfica, 7(14), 64-73.

De León, K., Ramírez, M., Sánchez, V., Ramírez, M., Salas, R., Santos, N., y Valadez, R. (2014). Effect of crude plant extracts from some Oaxacan flora on two deleterious fungal phytopathogens and extract compatibility with a biofertilizer strain. Frontiers in Microbiology, 5(383), 1-11. https:// doi.org/10.3389/fmicb.2014.00383

De León, M., Sáenz, A., Jasso, D., Rodríguez, R., Pandey, A., y Aguilar, C. (2013). Fermented Flourensia cernua extracts and their in vitro assay against Penicilium expansum and Fusarium oxysporum. Food Technology and Biotechnology, 51(2), 233-239.

Delporte, C., (2010). Farmacognosia, Santiago de Chile, Chile: Departamento de química farmacológica y toxicológica.

Food and Agriculture Organization of the United Nations (FAO). (2018). Rice Market Monitor (RMM). (Vol. 21). Retrieved from http://www.fao.org/3/ i9243en/I9243EN.pdf

Flor, H, \& Parra, M. (2017). Estandarización fitoquímica de extractos hidroalcohólicos de ishpink, Ocotea quixos (Lam.) Kostern (tesis de pregrado). Universidad Politécnica Salesiana, Quito, Ecuador.

Fraga, M., García, P., Pereira, A., Lourenço, C., Jimenez, C., Prieto, M., y Simal, J. (2020). Technological application of tannin based extracts. Molecules, 25(614), 1-27.

He, D., Li, Y., Tang, H., Luo, L., Ma, R., Wang, J., y Wang, L. (2016). Phenolic compounds from the twigs and leaves of tara (Caesalpinia spinosa). Journal of Asian Natural Products Research, 18(4), 334-338. https://doi.org/10.1080/102860 20.2015.1096269

Jasso de Rodríguez, D., Trejo, F., Rodríguez, R., Díaz, M., Sáenz, A., Hernández, F., ... Peña, F. (2015). Antifungal activity in vitro of Rhus mueIleri against Fusarium oxysporum f. sp. lycopersici. Industrial Crops and Products, 75, 150-158. https://doi.org/10.1016/j.indcrop.2015.05.048

Játiva, S. (2011). Determinación del contenido de taninos procedentes del guarango (Caesalpinia 
spinosa) y evaluación de su uso como fungicida (tesis de pregrado). Escuela Politécnica Nacional, Quito, Ecuador.

Kardel, M., Taube, F., Schulz, H., Schu, W., y Gierus, M. (2013). Different approaches to evaluate tannin content and structure of selected plant extracts - review and new aspects. Journal of Applied Botany and Food Quality, 86, 154-166. https://doi.org/10.5073/JABFQ.2013.086.021

Lage, L., Panizo, M., Ferrara, G., y Reviakina, V. (2013). Validación del inóculo por densitometría para las pruebas de susceptibilidad a los antifúngicos en especies del género Fusarium. Revista de La Sociedad Venezolana de Microbiología, 33, 46-52.

Laxmishree, C., y Nandita, S. (2017). Botanical pesticides - a major alternative to chemical pesticides: A review. International Journal of Life Sciences, 5(4), 722-729.

Leslie, J., y Summerell, B., (2006). The fusarium laboratory manual, Iowa, United States: Blackwell Publishing. https://doi. org/10.1002/9780470278376

Markom, M., Hasan, M., Wan Daud, W. R., Singh, H., y Jahim, J. (2007). Extraction of hydrolysable tannins from Phyllanthus niruri Linn. Effects of solvents and extraction methods. Separation Purification Technology, 52, 487-496. https://doi. org/10.1016/j.seppur.2006.06.003

Markom, M., Hasan, M., y Wan Raml, W. D. (2010). Pressurized water extraction of hydrolysable tannins from Phyllanthus niruri Linn. Separation Science and Technology, 45, 548-553. https:// doi.org/10.1080/01496390903485005

Melgarejo, P., García, J., Jordá, M., López, M., Andrés, M., y Duran, N., (2010). Patógenos de plantas descritos en España, España: Ministerio de Medio Ambiente y Medio Rural y Marino.

Melo, M., Glorio, P., y Tarazona, G. (2013). Efecto de la madurez en los componente de valor comercial (taninos y goma) de tara Caesalpinia spinosa (Molina) Kuntze. Revista de La Sociedad Química Del Perú, 79(3), 218-228.

Murga, H., Abanto, C., y Polo, A. (2016). Aspectos biológicos y control de un gracilláriido (Gracillariidae: Lepidóptera) en Caesalpinia spinosa (Mol.) Kuntze (1898), en Cajamarca, Perú. Scientia Agropecuaria, 07(02), 93-102. https://doi. org/10.17268/sci.agropecu.2016.02.02
Muthayya, S., Sugimoto, J. D., Montgomery, S., y Maberly, G. F. (2014). An overview of global rice production, supply, trade, and consumption. Annals of the New York Academy of Sciences (Vol. 1324). https://doi.org/10.1111/nyas. 12540

Nava, E., García, C., Camacho, J., y Vázquez, E. (2012). Bioplaguicidas: una opción para el control biológico de plagas. Ra Ximhai, 8(3), 17-29.

Nieto, C., y Barahona, N., (2006). Cadenas agroproductivas para la conservación de la cuenca media del río Pita, Quito, Ecuador: Fondo para la protección del agua.

Nuñez, J., Quiala, E., Feria, M., Mestanza, S., Gómez, R., Cuadrado, F., y Leiva Mora, M. (2017). Establecimiento de un banco clonal de Caesalpinia spinosa (Mol.) O. Kuntz mediante selección de árboles plus e injerto. Biotecnología Vegetal, 17(1), 41-49.

Pacin, A., González, H., Etcheverry, M., Resnik, S., Vivas, L., y Espin, S. (2002). Fungi associated with food and feed commodities from Ecuador. Mycopathologia, 156(2), 87-92. https://doi. org/10.1023/A:1022941304447

Refai, M., Hassan, A., y Hamed, M., (2015). Monograph on the genus Fusarium, Cairo, Egypt. https://doi.org/10.13140/RG.2.1.3104.2728

Rodríguez, A., Morales, D., y Ramírez, M. (2000). Efecto de extractos vegetales sobre el crecimiento in vitro de hongos fitopatógenos. Cultivos Tropicales, 21(2), 79-82. https://doi.org/10.1234/ct.v21i2.744

Rodríguez, A., Ramírez, M., Bautista, S., Cruz, A., y Rivero, D. (2012). Actividad antifúngica de extractos de Acacia farnesiana sobre el crecimiento in vitro de Fusarium oxysporum f. sp. Iycopersici. UDO Agrícola, 12(1), 91-96.

Ruiz, J., Soto, R., San Migue, R., Pérez, D., Tapia, R., Ortiz, E., y Rodríguez, C. (2016). Diospyros cuneata inhibition of Fusarium oxysporum: aqueous extract and its encapsulation by ionic gelation. Plant Pathology \& Microbiology, 7(2), 1-7. https://doi.org/10.4172/2157-7471.100033

Salhi, N., Ayesh, S., Saghir, M., Terzi, V., Brahmi, I., Ghedairi, N., y Bissati, S. (2017). Antifungal activity of aqueous extracts of some dominant algerian medicinal plants. BioMed Research International, 2017, 1-6.

Schöneberg, T., Kibler, K., Sulyok, M., Musa, T., Bucheli, D., Mascher, F., ... Voegele, R. (2018). 
Can plant phenolic compounds reduce Fusarium growth and mycotoxin production in cereals ?. Food Additives and Contaminants - Part A. 1-16. https://doi.org/10.1080/19440049.2018.1538570

Skowyra, M. (2014). Antioxidant properties of extracts from selected plant materials (Caesalpinia spinosa, Perilla frutescens, Artemisia annua and Viola wittrockiana) in vitro and in model food systems (PhD thesis). Universidad Poltécnica de Cataluña, Barcelona, España.

Soković, M., Glamočlija, J., y Ćirić, A. (2013). Natural products from plants and fungi as fungicides. In M. Nita. (Ed.), Fungicides - showcases of integrated plant disease management from around the world (pp. 186-232). Virginia, United States. http://dx.doi.org/10.5772/50277

Solis, A. (2016). Alternativas biológicas para el manejo del complejo de manchado de grano en el cultivo de arroz en Babahoyo provincia de los Ríos (tesis de pregrado). Universidad de Guayaquil, Guayaquil, Ecuador.

Tabarelli, B., Berghetti, J., Zanella, E., y Trezzi, R. (2019). Symptoms of Fusarium graminearum infection in irrigated rice grains. Ciência Rural, 49(03), 2019. https://doi.org/10.1590/0103$8478 \mathrm{cr} 20180831$

Veloz, R., Marín, R., López, M., Veloz, R., y Guevara, L. (2012). Evaluación del efecto de concentrados de taninos sobre el crecimiento micelial de hongos fitopatogenos. Celaya.

Villa, A., Pérez, R., Morales, H., Basurto, M., Soto, J., y Martínez, E. (2014). Situación actual en el control de Fusarium spp. y evaluación de la actividad antifúngica de extractos vegetales. Acta Agronomica, 64(2). https://doi.org/10.15446/ acag.v64n2.43358

Villanueva, R., Aguilar, A., Gómez, M., Valencia, G., Piña, B., y Bautista, S. (2013). Control de bacterias patógenas y hongos postcosecha con extractos del pigmento de Gibberella zeae ( $F u$ sarium graminearum). Agrociencia, 47, 691-705.

Wang, C., Chen, H., Wu, J., y Chen, L. (2019). Stability of principal hydrolysable tannins from Trapa taiwanensis Hulls. Molecules, 24(365), 1-11. https://doi.org/10.3390/molecules24020365
Conflicto de Intereses Los autores declaran no tener ningún conflicto de intereses 